adentro afuera

\title{
dedans dehors
}

Le corps n'est que dehors: peau exposée, réseau de receveurs et d'émetteurs sensibles. Tout en dehors et rien comme un "moi" qui se tiendrait enveloppé à l'intérieur. Pas de fantôme dans la machine, rien, le point sans dimension où "je" sens et me sens sentir. Le dedans de l'enveloppe n'est encore qu'un autre dehors développé autrement, tout en replis, retours, convolutions et adhérences, tout invaginations, amoncellements et conglomérats.

Il se sent à peine puisque tout $y$ touche tout dans une épaisseur continue. Tout s'y touche, tout s'y mêle, tout s'y glisse dans le silence des organes qui ne s'offrent entre eux ni vues, ni goûts, ni odeurs, ni sons et pour finir à peine un toucher puisqu'il est, ce dedans, si constant, si épais, si bien pris dans la masse compacte et solidaire que le corps intérieur est sans organes. Etant au dehors de moi comme ce dedans dans lequel il n'est pas question de pénétrer-sauf à m'éventrer ou à m'étouffer-il est dehors indéfiniment emballé, absorbé, enfoncé dans son propre magma partout bien ajusté à lui-même et parfaitement étranger à ce qu'il remplit, à ce qu'il soutient et anime: toute cette peau exposée avec ses orifices, ses muqueuses, ses pores, ses poils, tous ses contacts et ses communications, toutes ses vibrations de monde, de matières et d'images, de timbres et d'assonances, toutes ces fumées et ces jets, ces courants d'air, ces miroirs, ces morceaux de métal, ces autres peaux, ces propos, ces impressions, ces dépressions, ces expressions.
Tout cela pourtant qu'il soutient de ses arcs-boutants, de ses colonnes, cages, tubes et membres, tout cela l'impressionne aussi. Cela s'exprime en lui et nulle part ailleurs. Le dehors exposén'a pas d'autre lieu que ce dedans pour y fourrer ses sensations tout autant que ses nourritures, l'air qu'il respire, les baisers, le savoir qu'il aspire. C'est là que ça sent et que ça se sent sentir, c'est dans l'estomac, l'intestin, aux palpitations du cœur, aux insufflations des poumons, pour ne rien dire des infiltrations sourdes qui cheminent de nerfs en muscles, de canaux lymphatiques en massifs hépatiques, en biles et en sucs de pancréas. La peau sent sous la peau, l'œil voit dans la gelée prise sous les méninges.

Mais je dis trop, je dis bien trop disant ces mots que j'ai appris d'un autre extérieur, d'une médecine ou d'une physiologie, d'une anatomie pour lesquelles les vésicules, les tendons, les péristaltismes ont un sens déterminé, fonctionnel, qui lorsqu'il m'est présenté me signifie tout autre chose que mon corps, dedans ou dehors: un dispositif, un appareil, un équipement branché sur des sondes, sur des produits chimiques, dissocié, disséqué par des lames ou par des aiguilles. Il est toujours intriguant, distrayant ou dérangeant de voir l'image échographique de ses artères ou bien celle du réseau des coronaires opacifié par un produit de contraste et projeté sur un écran depuis la sonde qu'on a introduite en ouvrant une veine à l'aine. Cela n'est qu'une représentation similaire aux résultats d'une analyse sanguine ou à une mesure spirométrique qui appartiennent à l'ensemble de la représentation, de la computation et de l'instrumentation physiologiques. 


\section{adentro afuera}

El cuerpo no es sino sólo afuera: piel expuesta, red de receptores y transmisores sensibles. Todo afuera y nada como un "yo" que se tuviera envuelto en el interior. Ningún fantasma en la máquina, nada, el punto sin dimensión donde "yo" siento y me siento sentir. El adentro de la envoltura no es sino otro afuera desenvuelto de otro modo, todo en recovecos, retornos, circunvoluciones y adherencias, todo invaginaciones, amontonamientos y conglomerados.

Se siente apenas porque todo toca todo en un espesor constante. Todo se toca, todo se mezcla, todo se desliza en el silencio de los órganos que no se ofrecen entre ellos ni vistas, ni sabores, ni olores, ni sonidos y para acabar apenas un toque porque es, este adentro, tan constante, tan espeso, tan bien sujeto a la masa compacta y solidaria que el cuerpo interior es sin órganos. Estando afuera de mí como este adentro en el cual no se trata de penetrar -salvo a desentrañarme o a atragantarme- está indefinidamente embalado, absorbido, empujado hacia su propio magma en todas partes bien ajustado a él mismo y perfectamente extraño a lo que llena, a lo que sostiene y anima: toda esta piel expuesta con sus orificios, sus mucosas, sus poros, sus pelos, todos sus contactos, y sus comunicaciones, todas sus vibraciones del mundo, de materias y de imágenes, de timbres y de asonancias, todos estos humos y estos chorros, estas corrientes de aire, estos espejos, estos pedazos de metal, estas otras pieles, estos propósitos, estas impresiones, estas depresiones, estas expresiones.
Todo esto, a pesar de que sostiene sus arbotantes, sus columnas, huecos, tubos y miembros, todo esto también lo impresiona. Esto se expresa en él y en ninguna otra parte. El afuera expuesto no tiene otro lugar sino este adentro para atiborrar sus sensaciones, así como sus alimentos, el aire que respira, los besos, el saber que aspira. Allí esto siente y se siente sentir, en el estómago, en el intestino, en las palpitaciones del corazón, en las insuflaciones de los pulmones, por no decir nada de las infiltraciones sordas que fluyen de los nervios en los músculos, de los canales linfáticos en las masas hepáticas, en las bilis y en los jugos del páncreas. La piel siente debajo la piel, el ojo ve en la gelatina presa debajo de las meninges.

Pero digo mucho, digo demasiado diciendo estas palabras que he aprendido de un otro exterior, de una medicina o de una fisiología, de una anatomía, para las cuales las vesículas, los tendones, los peristaltismos tienen un sentido determinado, funcional, que cuando se me presenta me significa cualquier otra cosa que mi cuerpo, adentro o afuera: un dispositivo, un aparato, un equipo conectado a las sondas, a los productos químicos, disociado, diseccionado por las cuchillas o por las agujas. Siempre es intrigante, entretenido o perturbador ver la imagen ecográfica de sus arterias o bien la red de coronarias opacada por contraste radiológico y proyectada en una pantalla desde la sonda que se ha introducido abriendo una vena en la ingle. Esta no es más que una representación similar a los resultados de un análisis sanguíneo o a una medida espirómetrica que pertenece al conjunto de la representación, de la computación y de la instrumentación fisiológica. 
adentro afuera

Il s'agit d'un autre sujet que celui qui se tient dessous -sub-jectum, sup-positum, sub-stantia- et qui en ce dessous ingère non seulement des aliments mais leurs goûts et avec eux les goûts de toutes choses, les chocs, les frottements, les grelots et les trompes, les humeurs et les pulsations, l'air, l'esprit, la chaleur, la tendresse, l'ennui, le désir. Ce sujet-là paraît assujetti à l'autre, au personnage qui se dit "moi", et pourtant cette personne n'est qu'une très mince feuille de contact, presque rien, un intervalle entre dessous et dessus, entre ces deux dehors qui lui font ce qu'il croit pouvoir dire un dedans. Mais là-dedans aussi ça se rapporte à soi, ça se sent, ça grogne ou ça gêne, ça crispe ou ça se détend. Il y résonne des borborygmes, il y passe des sifflements, il s'y dresse des érections. A tout instant, à tout endroit, la peau imprime à son revers -houppes, fibres, fascicules nerveux - tous les messages -images, ramages, nuages- qui me signalent rien de plus, rien de moins que ma présence au monde. Or elle est aussi, cette présence, exposée à même mes entrailles, à même mes intestins qui sont selon leur nom le dedans même, non loin de l'intime, non loin de l'interior intimo meo augustinien et pas loin de l'interfeces et urinam de même mouture, tout près du dieu excellent comme de l'excrément infâme. Ce qui sort et ce qui entre, merde ou pensée, parole ou salive, excitation, excoriation, tout va de pair et de conserve d'un dehors l'autre, constant murmure et remuement du même ensemble en soi tout entier hors de moi. Moi je reste l'intime point nul d'un esprit nulle part localisé dans cet empêtrement barbouillé de pulpes, de tissus, de fluides qui donne lieu en son entier à cette âme qu'il faut concevoir étendue partout le long des vaisseaux et des téguments, nouée des nœuds lymphatiques et baignée de plasma.
Il n'y a pas de représentation de ce dehors qui grouille dedans, ou bien ce sont des coupes sur lamelles, des imageries à résonance magnétiques ou des scanners à émission de positons. Cependant il ne faut pas se presser trop de récuser les anatomies, les histologies ni les physiologies: leur étrangeté technique ne laisse pas de nous rappeler que c'est quand même nous. En quelque manière il faut bien que mon œil soit vitreux, aqueux, irisé; que mon doigt soit osseux, tendineux, ongulé. Ces choseslà ne sont pas tout à fait des choses et la planche d'anatomie garde le trouble d'un miroir secret. L'écorché moulé en résine, avec ses organes rouges, bruns et bleus, ou le squelette de plastique blême aux 367 os crochetés en ordre me disent ou me peignent moi-même, comment l'ignorer? Comment donc ignorer quel point je suis loin, à quel point méconnaissable, étrangement inquiétant? 
Se trata de un otro sujeto que el que se tiende debajo -sub-jectum, sup-positum, sub-stantia- y que en ese debajo ingiere no sólo alimentos, sino sus sabores y con ellos los sabores de todas las cosas, los choques, los frotamientos, los cascabeles y las trompas, los humores y las pulsaciones, el aire, el espíritu, el calor, la ternura, el aburrimiento, el deseo. Este sujeto-ahí parece sujeto al otro, al personaje que se dice "yo", y sin embargo esta persona no es sino una hoja de contacto muy delgada, casi nada, un intervalo entre debajo y encima, entre estos dos afuera que lo hacen esto que cree poder decir un adentro. Pero allá adentro también eso se refiere a sí, eso se siente, eso gruñe o eso molesta, eso crispa o se afloja. Resuena de borborigmos, echa silbidos, levanta erecciones. En cualquier instante, en cualquier lugar la piel imprime a su reverso -borlas, fibras, fascículos nerviosos- todos los mensajes -imágenes, ramajes, nubesque me señalan nada más y nada menos que mi presencia en el mundo. $\mathrm{O}$ es también, esta presencia, expuesta hasta mis mismas entrañas, hasta mis intestinos que son según su nombre el adentro mismo, no lejos de lo íntimo, no lejos del interior intimo meo agustiniano y no lejos del interfeces et urinam de la misma molienda, todo cerca del dios excelente como del excremento infame. Lo que sale y lo que entra, mierda o pensamiento, palabra o saliva, excitación, excoriación, todo a la par y conjuntamente de un adentro al otro, murmullo constante y movimiento del mismo conjunto en sí entero fuera de mí. Sigo siendo el punto nulo íntimo de un espíritu que en ninguna parte se localiza en esta trabazón embadurnada de pulpas, de tejidos, de fluidos que da lugar en su totalidad a esta alma que es necesario concebir extensa a lo largo de vasos y tegumentos, anudado de nodos linfáticos y bañado de plasma.
No hay una representación de este afuera que hormiguea dentro, o bien son secciones sobre láminas, imágenes de resonancia magnética o escáneres de emisión de posiciones. Sin embargo no es necesario apresurarse demasiado en recusar las anatomías, las histologías ni las fisiologías: su extrañeza técnica no deja de recordarnos que es a pesar de todo nosotros. De alguna manera es muy necesario que mi ojo sea vidrioso, acuoso, irisado; que mi dedo sea óseo, fibroso, ungulado. Estas cosas no son del todo cosas y la plancha de anatomía guarda el desconcierto de un espejo secreto. La figura anatómica desollada moldeada en resina, con sus órganos rojos, cafés y azules, o el esqueleto de plástico descolorido de 367 huesos enganchados en orden me dicen o me rastrillan a mí mismo, ¿cómo ignorarlo? ¿Cómo, pues ignorar hasta qué punto estoy lejos, hasta qué punto irreconocible, extrañamente inquietante? 